\title{
A TEORIA DO GANHO AMBIENTAL E AS CONSTRUÇÕES EM ÁREAS DE PRESERVAÇÃO PERMANENTE - APP
}

\section{THE ENVIRONMENTAL GAIN THEORY AND CONSTRUCTIONS IN PERMANENT PRESERVATION AREAS - PPA}

\section{Rafael Lima Daudt D'Oliveira ${ }^{1}$}

\section{RESUMO}

O artigo analisa a possibilidade de aplicação da teoria do ganho ambiental a alguns casos de construções realizadas em Áreas de Preservação Permanente (APPs), áreas consideradas não edificantes pela legislação. Para tanto, examina-se os requisitos para a aplicação da referida teoria, com base nos princípios do direito ao meio ambiente equilibrado, do no net loss (impossibilidade de perda líquida), da razoabilidade, da proporcionalidade e da segurança jurídica. Concluindo, defendese que, em alguns casos concretos, deve-se ponderar entre o desfazimento e a manutenção das intervenções para verificar qual solução é a mais benéfica para o meio ambiente. A melhor solução pode consistir, justamente, na escolha pela manutenção da construção em APP.

Palavras-chave: Teoria do ganho ambiental - Áreas de preservação permanente - Meio ambiente equilibrado - Impossibilidade de perda líquida - Solução mais benéfica

\section{ABSTRACT}

The article analyzes the possibility of applying the theory of environmental gain to some cases of constructions carried out in Permanent Preservation Areas (PPAs), areas considered not edifying by law. Therefore, the requirements for the application of that theory are examined, based on the principles of the right to a balanced environment, no net loss, reasonableness, proportionality and legal certainty. In conclusion, it is argued that, in some concrete cases, it is necessary to consider between the undoing and maintenance of interventions to verify which solution is the most beneficial for the environment. The best solution may consist precisely in choosing to maintain the construction in PPAs.

\footnotetext{
${ }^{1}$ Doutorando em Direito Público e Mestre em Direito Ambiental e Urbanístico pela Universidade de Coimbra, Portugal. Especialista em Direito Ambiental e Bacharel em Direito pela Puc-Rio (Pontifícia Universidade Católica do Rio de Janeiro). Professor de Direito Ambiental da Puc-Rio. Professor de Direito Administrativo e Ambiental da ESAP-Escola Superior da Advocacia Pública. Ex-Conselheiro do CONAMA e do CONEMA-RJ. Ex-Procuradorchefe do Instituto Estadual do Ambiente-RJ. Procurador do Estado do Rio de Janeiro. Sócio do escritório Daudt Advogados. Autor do livro "A Simplificação no Direito Administrativo e Ambiental". Autor de diversas publicações sobre direito ambiental no Brasil e na Europa. Afiliação: Pontifícia Universidade Católica do Rio de Janeiro - PUCRio. ORCID:https://orcid.org/0000-0001-8566-4911 E-mail: rafaeldaudt@hotmail.com
} 
Keywords: Environmental gain theory - Permanent preservation areas - Balanced environment - Net loss impossibility - Most beneficial solution

\section{1 - INTRODUÇÃO}

No presente trabalho, analisamos a possibilidade de aplicação da teoria do ganho ambiental a alguns casos de construções realizadas em Áreas de Preservação Permanente (APPs), áreas consideradas não edificantes pela legislação. Para tanto, examinamos os requisitos para a aplicação da referida teoria, com base nos princípios do direito ao meio ambiente equilibrado, do no net loss (impossibilidade de perda líquida), da razoabilidade, da proporcionalidade e da segurança jurídica. Em resumo, defendemos que, em alguns casos concretos, deve-se ponderar entre o desfazimento e a manutenção das intervenções para verificar qual solução é a mais benéfica para o meio ambiente. A melhor solução pode consistir, justamente, na escolha pela manutenção da construção em APP.

\section{2 - ÁREA DE PRESERVAÇÃO PERMANENTE ('APP'): IMPOSSIBILIDADE DE INTERVENÇÃO FORA DAS HIPÓTSES PREVISTAS NA LEGISLAÇÃO}

O artigo 3ำ, II, da Lei 12.651/2012 define área de preservação permanente como "área protegida, coberta ou não por vegetação nativa, com a função ambiental de preservar os recursos hídricos, a paisagem, a estabilidade geológica e a biodiversidade, facilitar o fluxo gênico de fauna e flora, proteger o solo e assegurar o bem-estar das populações humanas". E o seu art. 4ㅇ define as espécies de APP protegidas pelo só efeito do Código Florestal, tais como as faixas marginais de cursos d'água, topos de morro, manguezais, entre outras. As APPs são consideradas áreas não edificantes, onde nada se pode construir, já que tais áreas devem ter destinação florestal, conforme leciona a doutrina. $^{2}$

No entanto, existem hipóteses em que é possível, de forma excepcional, a supressão e/ou intervenção em APP. Com efeito, tais hipóteses excepcionais são aquelas previstas: (i) no art. 3o, incisos VIII, IX e X, c/c art. 8ㅇ, todos do Código Florestal (Lei 12.651/12), nos casos de utilidade pública, interesse social ou baixo impacto ambiental; (ii) em Resolução do Conselho Estadual de Meio Ambiente que preveja outras ações reconhecidas como eventuais e de baixo impacto ambiental, conforme alínea " $k$ " do inciso X do art. 3o da Lei 12.651/12³; (iii) em decreto do chefe do Poder Executivo Estadual, de

\footnotetext{
2 MACHADO, Paulo Affonso Leme, Direito Ambiental Brasileiro. 12ª ed. São Paulo, Malheiros, 2004, p. 709.

${ }^{3}$ Art. 3ํㅡㄹ Para of eitos desta Lei, entende-se por: (...)
} 
caráter geral e abstrato, nos casos de utilidade pública e interesse social, nos termos da alínea "e" do inciso VIII e alínea "'g" do inciso IX, ambos do artigo 3o da Lei 12.651/20124.

Sabe-se que, ao longo dos anos, diversas construções que não se enquadram nas exceções previstas na legislação foram realizadas em APPs. Não são passíveis de regularização com fundamento nos dispositivos legais acima mencionados. Contudo, muitas vezes foram realizadas há muito, por desconhecimento da própria legislação e o seu desfazimento não se justifica em termos de ganho ambiental.

De todo modo, antes de enfrentarmos o assunto referente à possibilidade ou não de manutenção das construções, cabe analisar a responsabilidade civil ambiental do infrator pelas intervenções em APP em hipóteses não autorizadas pela legislação.

\section{3 - REPONSABILIDADE CIVIL PELO DANO AMBIENTAL: DA INAPLICABILIDADE DA TEORIA DO FATO CONSUMADO EM TEMA DE DIREITO AMBIENTAL E DA IMPRESCRITIBILIDADE DA PRETENSÃO DE REPARAÇÃO DO DANO AO MEIO AMBIENTE}

O Superior Tribunal de Justiça pacificou o entendimento sobre a inaplicabilidade da teoria do fato consumado em matéria ambiental. Com efeito, a Corte Superior editou, em 2018, a Súmula 613, que assim dispõe: "Não se admite a aplicação da teoria do fato consumado em tema de direito ambiental."

Vale citar o seguinte julgado do STJ para melhor compreensão desta matéria:

“DIREITO ADMINISTRATIVO. ENUNCIADO ADMINISTRATIVO 2/STJ. AÇÃO CIVIL PÚBLICA AMBIENTAL. EDIFICAÇÃO EM ÁREA DE PROTEÇÃO PERMANENTE. MARGEM DO RIO INVINHEMA/MS. CASAS DE VERANEIO. FATO CONSUMADO EM MATÉRIA AMBIENTAL. INEXISTÊNCIA. (...)

3. Ocorre que a teoria do fato consumado em matéria ambiental equivale a perpetuar, a perenizar um suposto direito que vai de encontro, no entanto, ao postulado do meio ambiente equilibrado como bem de uso comum do povo essencial à sadia qualidade de vida, assim como é repelido pela nossa jurisprudência e pela mais alta Corte do país (v.g. STJ: REsp 948.921/SP, Rel. Min. Herman Benjamin, Segunda Turma, DJe de 11/11/2009; STF: RE 609748 AgR, Rel. Min. Luiz Fux, Primeira Turma, DJe de 19/9/2011)."

(...) (REsp 1.510.476/MS, Rel. Ministro Mauro Campbell Marques, Segunda Turma, DJe 14/11/2017) (grifou-se)

$\mathrm{X}$ - atividades eventuais ou de baixo impacto ambiental: (...)

k) outras ações ou atividades similares, reconhecidas como eventuais e de baixo impacto ambiental em ato do Conselho Nacional do Meio Ambiente - CONAMA ou dos Conselhos Estaduais de Meio Ambiente;

${ }^{4}$ Nesse sentido, é o Parecer RD 05/2007 da Procuradoria-Geral do Estado do Rio de Janeiro. 
Em relação à prescrição da pretensão relativa à ação com pedido de reparação do dano ambiental, o STF fixou, no julgamento do RE 654.833, o Tema 999 de Repercussão Geral, segundo o qual "É imprescritível a pretensão de reparação civil de dano ambiental." ${ }^{5}$. Este entendimento já vinha sendo aplicado anteriormente pelo STJ. Vejamos:

\begin{abstract}
"ADMINISTRATIVO E PROCESSUAL CIVIL. AÇÃO CIVIL PÚBLICA. DANO AMBIENTAL. IMPRESCRITIBILIDADE DA AÇÃO. ACEITAÇÃO DE MEDIDA REPARATÓRIA. REVOLVIMENTO DE FATOS E PROVAS. IMPOSSIBILIDADE. INCIDÊNCIA DA SÚMULA 7/STJ. CONTROVÉRSIA NÃO DESLINDADA PELA ORIGEM. AUSÊNCIA DE PREQUESTIONAMENTO. DIVERGÊNCIA JURISPRUDENCIAL. INEXISTÊNCIA DE IDENTIDADE FÁTICA E JURÍDICA. DA IMPOSSIBILIDADE DE INOVAÇÃO DE FUNDAMENTOS QUE NÃO FORAM OBJETO DE ANÁLISE PELA CORTE A QUO.

1. Trata-se de Ação Civil Pública que visa não só discutir a obrigação de reparação do dano, mas a de não degradação de área de preservação. 0 pedido inicial abrange não só a cessação dos atos, mas a elaboração de plano de recuperação e sua execução, após a demolição do empreendimento existente no imóvel situado à área de proteção. 2. A jurisprudência desta Corte é firme no sentido de que as infrações ao meio ambiente são de caráter continuado, motivo pelo qual as ações de pretensão de cessação dos danos ambientais são imprescritíveis. (...)" (Agravo Regimental no REsp 1421163, Rel. Ministro Humberto Martins, Segunda Turma, DJe 17/11/2014) (grifou-se)
\end{abstract}

Portanto, a consolidação de intervenções irregulares por tempo superior ao prazo prescricional das infrações administrativas não afasta a pretensão de reparação do dano ambiental, seja pela sua imprescritibilidade, seja pela inaplicabilidade da teoria do fato consumado em tema de meio ambiente.

Contudo, há outros fundamentos a serem analisados, para que se possa concluir pela permanência ou não, conforme a hipótese, das construções no local, como se passa a demonstrar.

\title{
4 - DA PONDERAÇÃO ENTRE A MANUTENÇÃO OU DESFAZIMENTO DE EDIFICAÇÕES EM ÁREAS PROTEGIDAS: TEORIA DO GANHO AMBIENTAL E REQUISITOS PARA A SUA APLICAÇÃO
}

A manutenção de construções em áreas ambientalmente protegidas, como as APPs, somente é possível caso seja demonstrado, mediante parecer técnico, que a manutenção das construções no local, bem como a reparação dos danos ambientais sugerida pelo órgão ambiental (por meio de medidas de recuperação e/ou compensação ambiental) são capazes de gerar um ganho ambiental. Na verdade, o que deve ser analisado é o que seria melhor para o meio ambiente: (i) desfazer as

\footnotetext{
${ }^{5}$ STF, RE 654.833, Tema 999 de Repercussão Geral, Rel. Min. Alexandre de Moraes, Pleno, julgado em 20.4.2020, publicado em 29.4.2020.
} 
construções irregulares em APP ou (ii) manter as referidas construções e exigir medidas mitigadoras e compensatórias.

É necessária, pois, a ponderação entre os impactos ambientais positivos e negativos advindos da manutenção ou da demolição das edificações irregulares. Nesse sentido, vale citar o princípio do no net loss (ou impossibilidade de perda líquida da biodiversidade), defendido pela doutrina e previsto na legislação de diversos países. Já tivemos oportunidade de registrar a respeito do referido princípio que:

"No net loss ou impossibilidade de perda líquida é uma expressão que vem sendo empregada cada vez mais em diversos países do mundo como um princípio, objetivo ou política, que tem por finalidade obter uma equivalência entre perdas e ganhos e, preferivelmente, um ganho líquido de valores da biodiversidade. (...) Para Anders Enetjärn et al. o objetivo das compensações é "alcançar o no net loss e preferivelmente um ganho líquido da biodiversidade no terreno com relação à composição de espécies, estrutura de habitats, funções ecossistêmicas e ao uso das pessoas e aos valores culturais associados à biodiversidade". ${ }^{6}$

\footnotetext{
${ }^{6}$ DAUDT D'OLIVEIRA, Rafael Lima. No Net Loss: um princípio entre a compensação ambiental e a preservação. In: Estado Social, Constituição e Pobreza - Estudos de Doutoramento III, vol. 5, Coimbra, Instituto Jurídico da Universidade de Coimbra, 2017, pp. 225-283.
} 
Valle dizer que Suécia ${ }^{7}$, Inglaterra ${ }^{8}$, Estados Unidos ${ }^{9}$, Canadá $^{10}$, Nova Zelândia ${ }^{11}$, Alemanha ${ }^{12}$ e Portugal ${ }^{13}$ também adotam o princípio do no net loss da biodiversidade em suas legislações referentes à compensação ambiental.

Esse princípio orienta a atividade estatal no sentido de envidar esforços para alcançar uma taxa zero de perda líquida (equivalência entre perdas e ganhos) e, preferivelmente, de um ganho líquido da biodiversidade. Portanto, serve para nortear o aplicador da norma na busca por uma solução cujos benefícios superem os prejuízos para o meio ambiente. Desse modo, diante de cada caso concreto e mesmo quando se tratar de áreas protegidas, deverá haver uma ponderação entre os benefícios e as desvantagens das possíveis soluções para determinada situação, e a decisão final deverá ser pautada em critérios que tragam o maior benefício para o meio ambiente.

\footnotetext{
${ }^{7}$ Confira-se o conceito de compensação ambiental (ekologisk compensation) que incorpora o princípio do no net loss: "Compensação ambiental é definida como a exigência para aqueles que causem danos ambientais para o ambiente natural - incluindo recursos públicos, como espécies, habitats naturais, funções ecossistêmicas e valores de usuário - devendo compensar essas perdas pela criação de novos valores com o explícito objetivo de evitar a perda líquida. A compensação ambiental deve apenas ser implementada depois de que todas as outras razoáveis medidas ambientais tenham sido tomadas na área afetada (v.g., para evitar ou minimizar impactos)". Anders ENETJäRN et al., Environmental compensation: Key conditions for increased and cost effective application, Nordic Council of Ministers, Copenhagen, 2015. Kindle Edition , (2.1). Tradução nossa.

8 O Defra britânico usa a seguinte definição de compensação ambiental, que não só incorpora o princípio do no net loss como de net gain (ganho líquido): "As compensações de biodiversidade são atividades de conservação que são projetadas para dar benefícios de biodiversidade para compensar perdas - assegurando que quando um desenvolvimento danifica a natureza (e este dano não pode ser evitado) novos, maiores ou melhores sítios naturais serão criados". Ibidem. Tradução nossa.

${ }^{9}$ Há vasta doutrina sobre o tema. Cf. Jessica OWLEY, «Preservation is a Flawed Mitigation Strategy», Ecology L. Currents, vol. 42, 2015, pp. 101-114; Virginia C. VELTMAN, «Banking on the Future of Wetlands Using Federal Law», Nw. U. L. Rev., vol. 89, 1994-1995, pp. 654-689; Shannon O'SHEA, «Lucas Leaves Room for Categorical Defenses for Regulations of Wetlands that Are Critical to Water Resources and Essential for Public Drinking»....; Steven L. DICKERSON, «The Evolving Federal Wetland Program», Sw. L.J., vol. 44, 1990-1991, pp. 1473-1497.

${ }^{10} \mathrm{Cf}$. a Habitat Policy, disponível em: http://www.dfo-mpo.gc.ca/Library/23654.pdf, acesso em 12/07/2017; Na doutrina, cf. Toby KRUGER, «The Canadian Environmental Assessment Act and Global Climate Change: Rethinking Significance», Alta. L. Rev., vol. 47, 2009-2010, pp. 161-183., Richard G. HILDRETH, «Managing Ocean Resources: Canada», Int'l J. Estuarine \& Coastal L., vol. 6, 1991, pp. 199-228; Austin WILLIAMS, «The Pacific Salmon Treaty: A Historical Analysis and Prescription for the Future», J. Envtl. L. \& Litig., vol. 22, 2007, pp. 153-195.

11 Cf. a National Policy Statement on Indigenous Biodiversity, Disponível em http://www.mfe.govt.nz/sites/default/files/media/Biodiversity/Proposed\%20National\%20Policy\%20Statement \%20on\%20Indigenous\%20Biodiversity_0.pdf, acesso em 17/06/2017. Na doutrina, cf. Stephanie TURNER, "Coastal Management and the Environmental Compensation Challenge», N.Z.J. Envtl. L., vol. 4, 2000, pp. 181200.

${ }^{12}$ OECD, Biodiversity Offsets: effective design and implementation, OECD Publishing, Paris, 2016, pp. 175-197; COLLINGWOOD ENVIRONMENTAL PLANNING LIMITED \& THE INSTITUTE FOR EUROPEAN ENVIRONMENTAL POLICY (IEEP), A review of recent biodiversity offsetting practice in Germany, 2014, disponivel em: http://randd.defra.gov.uk/Document.aspx?Document=12533_BiodiversityOffsettingreportfromGermanyDec20 14.pdf., acesso em 14/07/2017.

${ }^{13}$ Em Portugal, a Lei de Bases do Ambiente (Lei no 19/2014), em seu art. 17/2, 'b', enquadra a compensação ambiental entre os instrumentos econômicos e financeiros e dispõe que ela se materializa "através da realização de projetos ou de ações que produzam um benefício ambiental equivalente ao dano ambiental causado", parecendo que este critério de equivalência incorpora a ideia de no net loss, ainda que com outro nome.
} 
Assim se diz porque, diante dos termos do art. 225 da CRFB, que determina ao Poder Público o dever de preservar o meio ambiente ecologicamente equilibrado para as presentes e futuras gerações, por meio de diversas medidas, chega-se à conclusão de que esse dever que lhe é imposto deve ser concretizado sempre na busca da melhor solução possível para o meio ambiente.

Em outras palavras, diante do caso concreto, deve o Poder Público realizar as suas tarefas da forma que gere os maiores benefícios ambientais possíveis, respeitados os outros direitos, valores e interesses que eventualmente estejam em jogo. Logo, em se verificando que a manutenção das construções em APP vai gerar maiores benefícios ambientais do que o seu desfazimento, essa opção é a que melhor promove o direito ao meio ambiente ecologicamente equilibrado.

Analisando situação semelhante, que envolve possível demolição de construção em APP, Guilherme José Purvin de Figueiredo afirma que a demolição não pode implicar piores impactos ambientais que a manutenção da construção. Vejamos:

\begin{abstract}
"Não é necessário invocar a regra do direito adquirido para solucionar tais hipóteses, mesmo porque não existe direito adquirido de degradar o meio ambiente. Aplicando-se, porém, o princípio da proporcionalidade, quando a reversão ao status original de APPs exigir a realização de obras de tal porte que acarretem significativo impacto ambiental e de vizinhança (arts. 36 a 38 do Estatuto da Cidade: demolições, retirada de camada asfáltica, problemas de tráfego, poluição sonora e visual, dentre outros) e, ainda, naquelas em que o custo da recuperação seja despropositado, a mesma não deverá ser exigida. (...) A contrario sensu, desde que os custos com a demolição de obras situadas em áreas de preservação permanente e o impacto ambiental provocado pelas próprias obras sejam de pequena monta, se comparados com os benefícios trazidos pela revitalização da APP, a exigência de sua recuperação será pertinente." ${ }^{14}$
\end{abstract}

Na mesma linha, Édis Milaré defende, com fundamento expresso na regra prevista no artigo 19 , $\S 3^{\circ}$, do Decreto Federal $n^{\circ} 6.514 / 2008$, a ponderação do órgão ambiental para verificar se a demolição irá trazer ganho ambiental. Para o autor, em caso negativo, ela deverá ser substituída por outras medidas necessárias à cessação e à mitigação do dano ambiental:

"Contudo, não será aplicada a penalidade de demolição quando, mediante laudo técnico, for comprovado que o desfazimento da obra poderá trazer piores impactos ambientais que sua manutenção, caso em que a autoridade ambiental, mediante decisão fundamentada, deverá, sem prejuízo das demais sanções cabíveis, impor as medidas necessárias à cessação e mitigação do dano ambiental." ${ }^{\prime 15}$ (grifamos)

Com efeito, o Decreto federal 6.514/2008 estabelece, em seu art. 19, §3ㅇ:

\footnotetext{
14 FIGUEIREDO, Guilherme José Purvin de. Curso de direito ambiental. 6ạ ed.. São Paulo, Editora Revista dos Tribunais. 2013. p. 418.

${ }^{15}$ MILARÉ, Édis. Direito do Ambiente. 8ạ ed., São Paulo, Editora Revista dos Tribunais. 2013. p. 919
} 


\begin{abstract}
“Não será aplicada a penalidade de demolição quando, mediante laudo técnico, for comprovado que o desfazimento poderá trazer piores impactos ambientais que sua manutenção, caso em que a autoridade ambiental, mediante decisão fundamentada, deverá, sem prejuízo das demais sanções cabíveis, impor as medidas necessárias à cessação e mitigação do dano ambiental, observada a legislação em vigor."
\end{abstract}

Muito embora a regra inserta no referido Decreto apenas seja aplicável à esfera federal, destacamos a importância da sua fundamentação (teoria do ganho ambiental), bem como a previsão expressa na legislação brasileira da impossibilidade de se proceder à demolição quando "for comprovado que o desfazimento poderá trazer piores impactos ambientais que sua manutenção".

Na jurisprudência, existe orientação semelhante de vários Tribunais. Com efeito, citamos a seguir acórdão representativo do Tribunal Regional Federal da 5a Região que entendeu pela manutenção parcial de construções ilegais em áreas de preservação permanente, justamente, com base na teoria do ganho ambiental ${ }^{16}$ :

"CONSTITUCIONAL E ADMINISTRATIVO. AÇÃO CIVIL PÚBLICA. DANO AMBIENTAL. OCORRÊNCIA. ÁREA DE PRESERVAÇÃO. DEMOLIÇÃO DAS EDIFICAÇÕES. MEDIDA DESARRAZOADA E DESPROPORCIONAL. COMUNIDADE INSTALADA NO LOCAL. MEDIDAS PARA NÃO OCORRÊNCIA DE NOVAS CONSTRUÇÕES. MANUTENÇÃO DA SENTENÇA. IMPROVIMENTO DO APELO. (...) 2. Ação civil pública que julgou improcedente o pedido formulado pelo Ministério Público Federal, por entender que, não obstante a ocorrência de dano ambiental, essa situação deve ser mitigada tendo em vista que a determinação da demolição das edificações no local, não faria retornar o meio ambiente ao seu estado originário antes das obras, em prejuízo da comunidade que ali se instalou, com amparo da Administração do Município de Meruoca/CE.

3. A realocação das pessoas que residem na área de proteção ambiental, com a demolição de toda a estrutura montada, incluindo os serviços públicos já existentes em prol das pessoas na localidade mencionada, traria ao Município de Meruoca/CE, um grande dispêndio financeiro, levando-se em consideração a situação financeira altamente precária que atinge os municípios de pequeno porte da região nordeste.

4. O risco e o dano ambiental com a manutenção da comunidade na área de preservação permanente em nada justifica a demolição das casas da mencionada localidade - cujo dano é irreversível, bem como dos serviços públicos já disponibilizados com a consequente realocação das pessoas que ali residem. Cumpre aos entes públicos envolvidos adotar medidas menos drásticas para minorar ao máximo o risco e o dano atualmente existente, inclusive evitando-se novas edificações.

5. Concluída a obra e constatado que o meio ambiente não será recuperado por sua demolição, o que somente agravaria os problemas sociais da região, é de se mantê-la íntegra. As sanções infligidas pelo juízo a quo são proporcionais

\footnotetext{
${ }^{16}$ Em idêntico sentido, os seguintes julgados: Apelação Cível n 0014235-85.2005.8.19.0003 - TJRJ/5a CC - Rel. Des(a). Maria Regina Fonseca Nova Alves - j. em 01/07/2014; Apelação Cível n 0003212-79.2004.8.19.0003 TJRJ/ 10ạ CC - Rel. Des. Celso Luiz de Matos Peres - j. em 25/04/2012; Apelação Cível no 0000675 88.2010.8.24.0059 - TJSC/1 a Câmara de Direito Público - Rel. Des. Paulo Henrique Moritz Martins Da Silva - j. em 25/09/2018; Apelação no 0005485-71.2004.8.26.0347 - TJSP/1a Câmara Reservada ao Meio Ambiente - Rel. Des. Dimas Rubens Fonseca - j. em 10/08/2017 - DJ 11/08/2017.
} 
à infração e adequadas à recuperação do meio ambiente e ao incremento da educação ambiental. - Interpretação social do conceito de meio ambiente e aplicação dos princípios da razoabilidade e da proporcionalidade. (...)

6. Apelação e remessa oficial improvidas." (Apelação Cível no 576658 - TRF 5a Região/1a Turma - Rel Des. Federal Rubens de Mendonça Canuto - j. em 30/07/2015, DJ 06/08/2015 - grifamos)

Registre-se, ainda, que o Superior Tribunal de Justiça também tem precedente no mesmo sentido:
“PROCESSUAL CIVIL E ADMINISTRATIVO. AÇÃO CIVIL PÚBLICA AMBIENTAL. AGRAVO REGIMENTAL INTERPOSTO PELO MINISTÉRIO PÚBICO FEDERAL. VIOLAÇÃO DO ART. 535 DO CPC/1973. NÃO OCORRÊNCIA. (...)
9. $O$ acórdão guerreado, quanto ao art. 944 do CC vigente, atende aos princípios da razoabilidade e da proporcionalidade, ao admitir, por um lado, a mantença das edificações existentes na área de preservação permanente, em razão da possibilidade de a demolição vir a causar dano ambiental maior do que aquele já imposto por força das construções consideradas ilegais, e condenando, por outro lado, as agravantes e outros no pagamento de indenização como forma de recompor o dano ambiental ocasionado pela permanência das casas na área de preservação permanente." (AgRg no Agravo em Recurso Especial no 338.744/ RJ - STJ/1a Turma, Rel. Min. Benedito Gonçalves, DJ 26/11/2016.) (Grifo nosso.)

Este entendimento adotado pelo STJ seguiu o voto-vista proferido pela Min. Regina Helena Costa no mesmo julgamento, assim fundamentado:

\begin{abstract}
"Constata-se que o acórdão embargado analisou a questão da equivalência entre a extensão do dano ambiental causado e a respectiva reparação, tendo sido ponderada e admitida a permanência das edificações existentes, ante a possibilidade de a demolição causar dano ambiental ainda maior do que o já perpetrado com as construções ilegais, consoante indicado na prova pericial."
\end{abstract}

Infere-se, pois, que a legislação federal, doutrina e jurisprudência chancelam a teoria do ganho ambiental, desde que fundamentada em parecer técnico. Assim, permite-se a manutenção das construções em APP quando os seus benefícios ambientais superarem aqueles com a sua demolição, devendo ser atendida a exigência quanto à adoção de medidas reparatórias dos danos ambientais (medidas de recuperação e compensatórias) capazes de garantir o equilíbrio ecológico do meio ambiente.

Na construção da teoria do ganho ambiental aplicam-se os princípios da razoabilidade ${ }^{17}$ e da proporcionalidade. De acordo com Humberto Ávila, o princípio da razoabilidade:

\footnotetext{
${ }^{17}$ A razoabilidade é assim definida por José dos Santos Cavalho Filho: "Razoabilidade é a qualidade do que é razoável, ou seja, aquilo que se situa dentro de limites aceitáveis, ainda que os juízos de valor que provocaram a conduta possam dispor-se de forma um pouco diversa. Ora, o que é totalmente razoável para uns pode não ser para outros. Mas, mesmo quando não o seja, é de reconhecer-se que a valoração se situou dentro dos standards da aceitabilidade. Dentro desse quadro, não pode o juiz controlar a conduta do administrador sob a mera alegação de que não a entendeu razoável. Não lhe é lícito substituir o juízo de valor do administrador pelo seu próprio, porque a isso se coloca o óbice da separação de funções, que rege as atividades estatais. Poderá,
} 


\begin{abstract}
"exige a consideração do aspecto individual do caso nas hipóteses em que ele é sobremodo desconsiderado pela generalização legal. Para determinados casos, em virtude de determinadas especificidades, a norma geral não pode ser aplicável, por se tratar de caso anormal. (...) No caso acima referido a regra geral, aplicável à generalidade dos casos, não foi considerada aplicável a um caso individual, em razão da sua anormalidade. Nem toda norma incidente é aplicável. É preciso diferenciar a aplicabilidade de uma regra da satisfação das condições previstas em sua hipótese. Uma regra não é aplicável somente porque as condições previstas em sua hipótese são satisfeitas. Uma regra é aplicável a um caso se, e somente se, suas condições são satisfeitas e sua aplicação não é excluída pela razão motivadora da própria regra ou pela existência de um princípio que institua uma razão contrária. Nessas hipóteses as condições de aplicação da regra são satisfeitas, mas a regra, mesmo assim, não é aplicada. (...) Essa concepção de razoabilidade corresponde aos ensinamentos de Aristóteles, para quem a natureza da equidade consiste em ser um corretivo da lei quando e onde ela é omissa, por ser geral. Essas considerações levam à conclusão de que a razoabilidade serve de instrumento metodológico para demonstrar que a incidência da norma é condição necessária, mas não suficiente para sua aplicação. Para ser aplicável, o caso concreto deve adequar-se à generalização da norma geral. A razoabilidade atua na interpretação das regras gerais como decorrência do princípio da justiça." (preâmbulo" e art. 3 da CF)."18
\end{abstract}

Desse modo, percebe-se que a demolição de construções em APP (art. 3ำ, II, do Código Florestal em vigor) - área, em regra, não edificante pelo efeito do Código Florestal - deve observar o referido princípio da razoabilidade, na medida em que "uma regra é aplicável a um caso se, e somente se, suas condições são satisfeitas e sua aplicação não é excluída pela razão motivadora da própria regra", conforme citado acima.

Ora, a razão motivadora da regra que não permite construções em APP é, justamente, a proteção do meio ambiente e da função ecológica da APP, desde que esta função seja a "de preservar os recursos hídricos, a paisagem, a estabilidade geológica e a biodiversidade, facilitar o fluxo gênico de fauna e flora, proteger o solo e assegurar o bem-estar das populações humanas" (art. 3ํ, II, do Código Florestal).

Assim sendo, em se constatando que a demolição da construção em APP trará mais prejuízos do que benefícios ao meio ambiente e, do outro lado da moeda, que a sua manutenção trará mais benefícios do que desvantagens, é incontestável que a regra que proíbe a intervenção em APP, nessas hipóteses, deve ser "excluída pela razão motivadora da própria regra", qual seja a proteção do meio ambiente e da função ecológica da APP.

isto sim, e até mesmo deverá, controlar os aspectos relativos à legalidade da conduta, ou seja, verificar se estão presentes os requisitos que a lei exige para a validade dos atos administrativos. Esse é o sentido que os Tribunais têm emprestado ao controle" (grifamos). CARVALHO FILHO, José dos Santos. Manual de Direito Administrativo. 27ạ edição. São Paulo, Editora Atlas, 2014. p. 41.

18 ÁVILA, Humberto. Teoria dos Princípios: da definição à aplicação dos princípios jurídicos. 8a ed.. São Paulo, Malheiros, 2008. p. 155. 
Quanto ao princípio da proporcionalidade, Luís Roberto Barroso ${ }^{19}$ leciona que ele se traduz na apreciação de três subprincípios: (i) da adequação, que exige que as medidas adotadas pelo Poder Público se mostrem aptas a atingir os objetivos pretendidos; (ii) da necessidade ou exigibilidade, que impõe a verificação da inexistência de meio menos gravoso para atingimento dos fins visados; e (iii) da proporcionalidade em sentido estrito, que é a ponderação entre o ônus imposto e o benefício trazido, para constatar se é justificável a interferência na esfera dos direitos dos cidadãos. ${ }^{20}$

Assim, para se concluir pela demolição ou não da construção em APP, é preciso, à luz do referido princípio da proporcionalidade, que o parecer técnico pertinente ao caso concreto verifique o seguinte: quanto ao subprincípio da adequação, se a norma que proíbe a intervenção e a manutenção de edificações em APP é apta ou não no caso concreto a promover a finalidade de proteção do meio ambiente e da função ecológica da APP. Isso exatamente para aferir se a demolição das construções é ou não, no caso concreto, medida adequada para promover a finalidade pretendida.

Quanto ao subprincípio da necessidade, se a manutenção de parte ou, mesmo, da totalidade das construções erguidas em APP constitui ou não o meio menos gravoso para o particular, para a proteção do meio ambiente e para garantir a função ecológica da APP do que a sua demolição Assim, cabe aferir se a demolição total da referida construção colidiria ou não com o subprincípio da necessidade.

Quanto ao subprincípio da proporcionalidade em sentido estrito, se a manutenção parcial ou total das construções, complementada com medidas reparatórias, é medida que traz mais benefícios e menos ônus ao meio ambiente e ao particular do que a demolição total das referidas construções. É dizer, deve-se aferir se a eventual demolição violaria ou não o subprincípio da proporcionalidade em sentido estrito.

Logo, o parecer técnico do órgão ambiental pode verificar, no caso concreto, que a demolição de construções em APPs é medida inadequada, desnecessária e desproporcional em sentido estrito, sugerindo a sua manutenção total ou parcial.

Em casos semelhantes à hipótese deste estudo, a jurisprudência vem prestigiando a manutenção de construções em APP, com base na teoria do ganho ambiental e nos princípios da

\footnotetext{
19 BARROSO, Luís Roberto. Interpretação e Aplicação da Constituição. 5a edição. São Paulo, Saraiva, 2003. P.20. ${ }^{20}$ Para Flávio Amaral Garcia o princípio da proporcionalidade é um "indutor da eficiência e da economicidade, pois obriga o gestor a avaliar a razoabilidade da medida adotada, comparando-a com outras alternativas possíveis e viáveis, proporcionando uma avaliação mais objetiva e calcada na efetivação do resultado que maximize o atendimento ao interesse público". GARCIA, Flávio Amaral. Licitações e contratos administrativos: casos e polêmicas. 4a ed.. São Paulo: Malheiros, 2016. p.76.
} 
razoabilidade e da proporcionalidade. Confira-se, por todos, precedente irretocável do Tribunal de Justiça do Rio Grande do Sul que trata, precisamente, do tema ${ }^{21}$ :

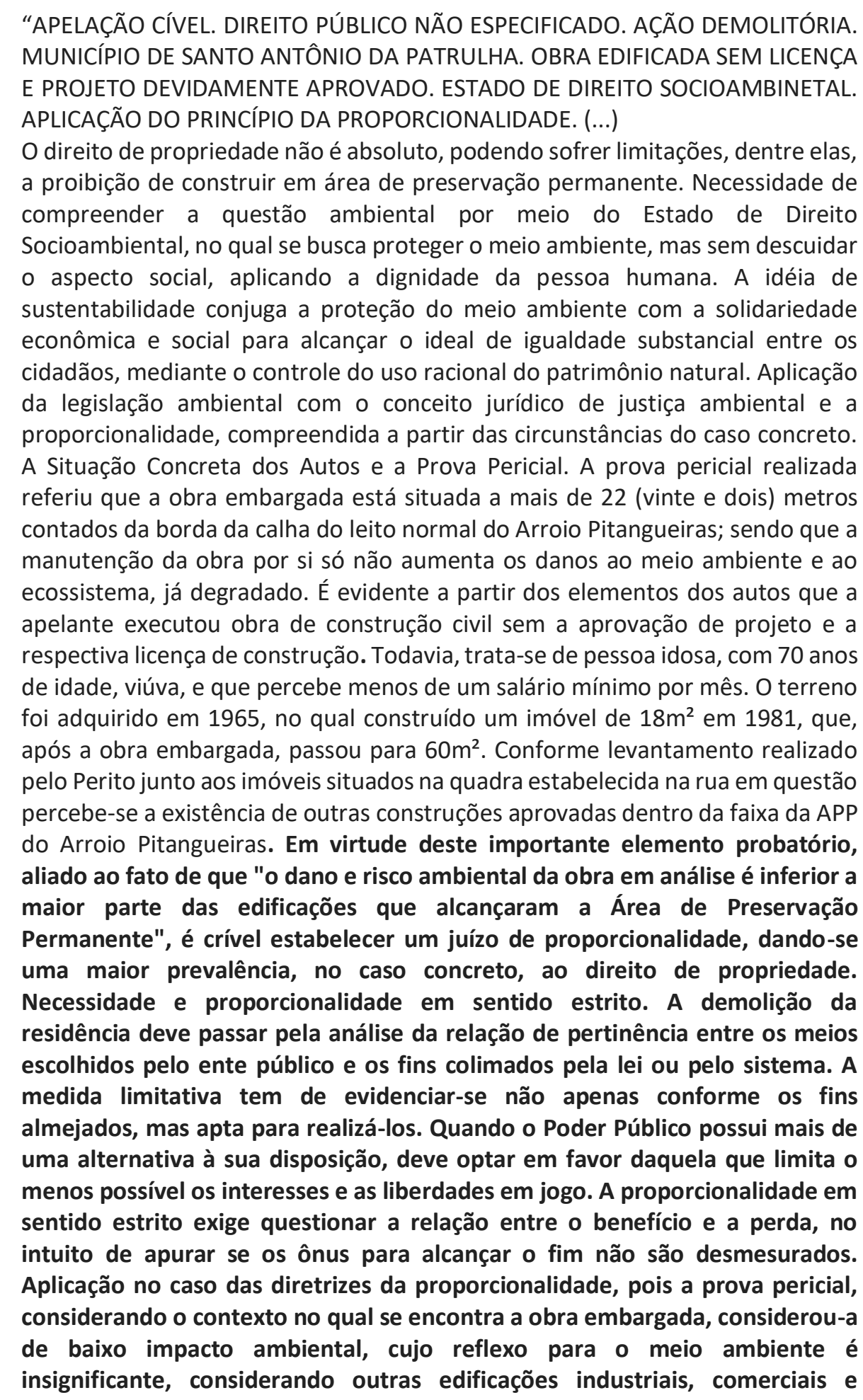

${ }^{21}$ No mesmo sentido, os seguintes julgados: Apelação no 0000758-73.1997.8.19.0003, TJRJ/2ạ Câmara Cível, Rel. Des(a). Leila Maria Carrilo Cavalcante Ribeiro Mariano - j. em 04/04/2007; Apelação Cível no 1.0435.15.0006607/001 - TJMG/ 1a CC - Rel. Des. Washington Ferreira, j. em 01/08/2017 - DJ 09/08/2017; Apelação Cível № 70025403551, TJRS/ 3a Câmara Cível, Rel. Des. Matilde Chabar Maia, j. em 11/12/2008; Apelação e Reexame Necessário no 70024443103 - TJRS/ 21aㅗ Câmara Cível - Rel. Des. Genaro José Baroni Borges - j. em 09/07/2008. 
residenciais existentes, além de prever a possibilidade de medidas de compensação. Precedentes desta Corte. Preliminar de incompetência rejeitada. Apelação provida. Ação julgada improcedente." (Apelação Cível no 70071079206 - TJRS/ 3a CC - Rel: Des. Leonel Pires Ohlweiler, j. em 15/12/2016) (grifamos)

Portanto, vê-se que a teoria do ganho ambiental, fundamentada no direito ao meio ambiente ecologicamente equilibrado, nos princípios no net loss, da razoabilidade e da proporcionalidade, encontra suporte em legislação federal, doutrina e jurisprudência pátrias. Pelas razões expostas, entendemos que a teoria do ganho ambiental se aplica não só no âmbito federal, mas também a Estados e Municípios.

Contudo, parece-nos insuficiente a aplicação automática da referida teoria, dissociada da fixação de um prazo em favor da segurança jurídica, bem como da imposição de medidas mitigadoras e compensatórias. Isso porque entendemos que pode haver uma banalização e uso desmedido da teoria do ganho ambiental, o que recomenda a adoção de três requisitos adicionais a título de cautela.

O primeiro requisito é que seja atestado por três servidores que a manutenção das construções é mais benéfica para o meio ambiente que o seu desfazimento. A exigência de três servidores se justifica em razão da necessidade de robusta fundamentação técnica para embasar a decisão, para o resguardo do órgão ambiental e do próprio meio ambiente, bem como para evitar fraudes ${ }^{22}$.

O segundo é o fator tempo. Nesse sentido, entendemos que, quando a construção tiver sido concluída há 10 (dez) anos ou mais, justifica-se a aplicação da teoria do ganho ambiental em homenagem ao princípio da segurança jurídica ${ }^{23}$.

Aqui a segurança jurídica milita em favor da estabilidade das relações socioambientais: o prazo de 10 (dez) anos serve, desse modo, como prazo mínimo a ser observado para a verificação da anterioridade da construção e para se presumir (presunção relativa) a efetiva interação do meio antrópico (construções) com o meio natural, como pressuposto para aplicação da teoria do ganho

\footnotetext{
${ }^{22} \mathrm{O}$ critério da utilização de três servidores para a elaboração e assinatura do parecer técnico foi adotado pelo Decreto Estadual no 42.356/2010, que conferiu caráter normativo ao Parecer RD 04/2007, prevendo hipótese excepcional de intervenção em APP que tenha perdido a sua função ecológica. Também a Lei Complementar 8/1977 do Estado do Rio de Janeiro, que trata do regime jurídico dos bens imóveis estaduais, prevê, em seu art. 11, parágrafo único: "Art. 11 - Qualquer aquisição onerosa de imóvel será precedida de sua avaliação, em laudo devidamente justificado. Parágrafo único - Quando esta lei exigir avaliação de imóvel, o laudo terá a responsabilidade de três (3) profissionais." (grifamos)

${ }^{23}$ Sobre segurança jurídica, confira-se a lição de Luís Roberto Barroso: "No seu desenvolvimento doutrinário e jurisprudencial, a expressão segurança jurídica passou a designar um conjunto abrangente de ideias e conteúdos, que incluem: 1) a existência de instituições estatais dotadas de poder e garantias, assim como sujeitas ao princípio da legalidade; 2) a confiança nos atos do Poder Público, que poderão reger-se pela boa-fé e pela razoabilidade; 3) a estabilidade das relações jurídicas, manifestada na durabilidade das normas, na anterioridade das leis em relação aos fatos sobre os quais incidem e na conservação de direitos em face da lei nova; 4) a previsibilidade dos comportamentos, tanto os que devem ser seguidos como os que devem ser suportados; a igualdade na lei e perante a lei, inclusive com soluções isonômicas para situações idênticas ou próximas." BARROSO, Luís Roberto. "O começo da história. A nova interpretação constitucional e o papel dos princípios no Direito brasileiro". In: Temas de Direito Constitucional, tomo III. Rio de Janeiro, Renovar, 2005, p. 133.
} 
ambiental (obviamente, essa interação depende de parecer técnico, não bastando apenas o decurso de tempo). Adota-se, aqui, o maior prazo de prescrição previsto no Código Civil - 10 (dez) anos ${ }^{24}$ - para o fim de aplicação da teoria do ganho ambiental. À falta de prazo expresso, o mais apropriado parece ser o emprego do maior prazo prescricional existente, aquele de 10 (dez) anos previsto no Código Civil, em homenagem à segurança jurídica e à proteção da confiança legítima ${ }^{25}$.

O terceiro requisito é a adoção das medidas mitigadoras e compensatórias especificadas pela área técnica do órgão ambiental. Se, por um lado, admite-se a regularização de construção em APP com base na teoria do ganho ambiental, desde que a construção tenha, pelo menos, 10 (dez) anos e haja parecer técnico atestando que a manutenção da construção é mais benéfica para o meio ambiente do que a sua demolição, por outro lado, é necessário sejam especificadas as medidas mitigadoras e compensatórias cabíveis.

Como houve ocupação irregular e danos ao meio ambiente, embora a teoria do ganho ambiental sugira a manutenção parcial das construções, isso não exime o particular da exigência de adoção das medidas de recuperação e compensação cabíveis, segundo critérios técnicos fixados pelo órgão ambiental.

Consigne-se, por necessário, que a teoria do ganho ambiental ora defendida tem por pressuposto a existência duma solução que gere benefícios ou vantagens para o meio ambiente, e, nesse sentido, não guarda relação e nem mesmo contraria a teoria da imprescritibilidade da pretensão de reparação do dano ambiental, tampouco a inaplicabilidade da teoria do fato consumado em tema de meio ambiente.

\section{5 - DA MATERIALIZAÇÃO DA TEORIA DO GANHO AMBIENTAL: CELEBRAÇÃO DE TERMO DE AJUSTAMENTO DE CONDUTA (TAC)}

Diante do exposto nos tópicos anteriores, entendemos que a materialização da teoria do ganho ambiental pode ocorrer mediante a celebração de Termo de Ajustamento de Conduta ('TAC'), para o fim de garantir a manutenção das construções e para a especificação das obrigações do particular referentes à execução das medidas mitigadoras e compensatórias fixadas pelo órgão ambiental, bem como para a remoção parcial das construções, se for o caso, conforme parecer da área técnica.

\footnotetext{
${ }^{24}$ Código Civil: "Art. 205. A prescrição ocorre em dez anos, quando a lei não lhe haja fixado prazo menor."

25 A segurança jurídica visa também "à proteção da confiança e das legítimas expectativas nutridas pelos cidadãos e agentes econômicos e sociais em relação às leis e atos da Administração Pública" (BINENBOJM, Gustavo. Uma teoria do direito administrativo: direitos fundamentais, democracia e constitucionalização. Rio de Janeiro, Renovar, 2006, pp. 176-177.).
} 
Quanto à celebração do TAC, cabem alguns comentários a seu respeito. É que a doutrina diverge tanto quanto à natureza jurídica do TAC como quanto ao seu conteúdo, ou seja, sobre o que pode e não pode dispor. As posições doutrinárias sobre a natureza jurídica do TAC variam entre transação, contrato, ato jurídico em sentido estrito, negócio jurídico ${ }^{26}$ e até mesmo reconhecimento de uma obrigação legal a ser cumprida ${ }^{27}$.

No entanto, divergimos dessas posições e concordamos com Marçal Justen Filho, que considera o TAC um acordo da AP: "nos casos em que, em face de controvérsia quanto à prática de condutas irregulares ou indesejáveis, o Estado e um ou mais particulares avençam solução consensual destinada a eliminar a incerteza e a disciplinar a sua conduta futura. A avença envolve a assunção pelo particular de obrigações de dar, fazer e não fazer, cujo adimplemento acarretará eliminação ou redução de sanções possíveis em vista de eventos passados, ou alteração do regime jurídico até então aplicável”28.

Vale ressaltar, também, que o próprio TAC pressupõe a adoção de meios mais flexíveis e efetivos para cessar a degradação ambiental, recuperar e/ou compensar os danos causados, podendo, inclusive, haver prazos mais dilatados para o cumprimento das obrigações, pois, caso contrário, não faria sentido celebrá-1o29.

Vale mencionar, ainda, que o STJ já decidiu que "o Termo de Ajustamento, por força de lei, encerra transação", considerando que "é nulo o título subjacente ao termo de ajustamento de conduta cujas obrigações não foram livremente pactuadas" ${ }^{30}$. Em outra decisão, entendeu esse Tribunal que o TAC tem natureza contratual ${ }^{31}$. Portanto, pelas razões expostas e com base no posicionamento do STJ, parece-nos que é plenamente possível a negociação em matéria ambiental por meio do TAC.

Reforça esse entendimento a recém-publicada Lei no 13.655/2018, que incluiu dispositivos na Lei de Introdução às Normas do Direito Brasileiro (LINDB), uma vez que o seu art. 26 estabelece que "para eliminar irregularidade, incerteza jurídica ou situação contenciosa na aplicação do direito público, inclusive no caso de expedição de licença", poderá a Administração "celebrar compromisso com os interessados" (caput), o qual "buscará solução jurídica proporcional, equânime, eficiente e compatível com os interesses gerais" (art. 26, §1ํ, I) e "não poderá conferir desoneração permanente

\footnotetext{
${ }^{26}$ Veja-se, por todos: MILARÉ, Édis. Direito do Ambiente, 10a ed.. São Paulo, Editora Revista dos Tribunais, 2015, pp. 1467-1469.

27 CARNEIRO, Paulo Cezar Pinheiro. Acesso à justiça: juizados especiais cíveis e ação civil pública: uma nova sistematização da teoria geral do processo, 2- ed.. Rio de Janeiro, Forense, 2000, p.119.

28 JUSTEN FILHO, Marçal. Curso de Direito Administrativo. 9a ed. atualizada e ampliada. São Paulo: Revista dos Tribunais, 2013. p. 475/476.

${ }^{29}$ Também sobre o tema: DAUDT D'OLIVEIRA, Rafael Lima. A simplificação no direito administrativo e ambiental. Rio de Janeiro, Lumen Juris, 2020, pp. 102-114 e 162-168.

${ }^{30}$ REsp 802060/RS - STJ/1a Turma - Rel. Min. Luiz Fux - j. em 17/12/2009 - DJe 22/02/2010.

${ }^{31}$ AgRg no AREsp 575474/DF - STJ/3a Turma - Rel. Marco Aurélio Bellizze - j. em 12/02/2015 - DJe 27/02/2015.
} 
de dever ou condicionamento de direito reconhecidos por orientação geral" (art. 26, §1ํ, III). Inferese, nesse contexto, que a regra trazida pela nova lei possibilita concluir que a negociação do TAC é passível de concessões recíprocas.

Isso porque, como observam Sérgio Guerra e Juliana Bonacorsi de Palma, "as previsões contidas no art. 26 da LINDB garantem os direitos na negociação e o atendimento ao fim público (...), sem incorrer no risco de subversão ou desnaturação pelo exercício do poder regulamentar". ${ }^{32}$

Assim sendo, uma vez cumpridos os requisitos expostos neste trabalho para a aplicação da teoria do ganho ambiental, deve ser celebrado TAC para especificar as medidas de recuperação e compensação, que podem envolver, inclusive, a remoção parcial das construções, conforme parecer da área técnica.

\section{6 - CONCLUSÃO}

É possível firmar entendimento sobre a concepção e aplicabilidade da teoria do ganho ambiental, com base no direito ao meio ambiente ecologicamente equilibrado, nos princípios do no net loss, da razoabilidade, da proporcionalidade e da segurança jurídica (além da previsão expressa na legislação federal), quando houver ocupação irregular em áreas não edificantes em APPs, desde que sejam observados, cumulativamente, os seguintes requisitos:

a) parecer técnico do órgão ambiental assinado por, pelo menos, 3 (três) servidores, atestando a efetiva interação do meio antrópico (construções) com o meio natural e que as vantagens da manutenção da construção superam os benefícios ambientais com a sua demolição;

b) o transcurso de, pelo menos, 10 (dez) anos a partir da data da construção;

c) a fixação de medidas mitigadoras e compensatórias pela área técnica do órgão ambiental.

A teoria do ganho ambiental pode ser aplicada por qualquer ente da federação, pelas razões expostas neste trabalho, muito embora apenas conte com previsão expressa na legislação federal. Para tanto, cabe a celebração de TAC, para o fim da especificação das obrigações referentes à reparação do dano (recuperação e compensação), na forma do parecer da área técnica.

\section{BIBLIOGRAFIA}

ÁVILA, Humberto. Teoria dos Princípios: da definição à aplicação dos princípios jurídicos. 8a ed.. São Paulo, Malheiros, 2008.

\footnotetext{
32 GUERRA, Sérgio, DE PALMA, Juliana Bonacorsi, Art. 26 da LINDB: Novo regime jurídico de negociação com a Administração Pública, Revista de Direito Administrativo, Rio de Janeiro, Edição Especial: Direito Público na Lei de Introdução às Normas de Direito Brasileiro - LINDB (Lei n 13.655/2018), p. 135-169, nov. 2018, p. 147.
} 
BARROSO, Luís Roberto. "O começo da história. A nova interpretação constitucional e o papel dos princípios no Direito brasileiro". In: Temas de Direito Constitucional, tomo III. Rio de Janeiro, Renovar, 2005.

BARROSO, Luís Roberto. Interpretação e Aplicação da Constituição. 5ạ edição. São Paulo, Saraiva, 2003.

CARNEIRO, Paulo Cezar Pinheiro. Acesso à justiça: juizados especiais cíveis e ação civil pública: uma nova sistematização da teoria geral do processo, 2ª ed.. Rio de Janeiro Forense, 2000.

CARVALHO FILHO, José dos Santos. Manual de Direito Administrativo. 27ạ edição. São Paulo, Editora Atlas, 2014.

COLLINGWOOD ENVIRONMENTAL PLANNING LIMITED \& THE INSTITUTE FOR EUROPEAN ENVIRONMENTAL POLICY (IEEP), A review of recent biodiversity offsetting practice in Germany, 2014, disponível em: http://randd.defra.gov.uk/Document.aspx?Document=12533_BiodiversityOffsettingreportfromGerm anyDec2014.pdf., acesso em 14/07/2017.

DAUDT D'OLIVEIRA, Rafael Lima. No Net Loss: um princípio entre a compensação ambiental e a preservação. In: Estado Social, Constituição e Pobreza - Estudos de Doutoramento III, vol. 5, Coimbra, Instituto Jurídico da Universidade de Coimbra, 2017.

DAUDT D'OLIVEIRA, Rafael Lima. O Princípio da Integração Ambiental e as Energias Renováveis, Dissertação de Mestrado na Área de Especialização em Ciências Jurídico-Políticas/Menção em Direito do Ordenamento, Urbanismo e Ambiente da Faculdade de Direito da Universidade de Coimbra.

DAUDT D'OLIVEIRA, Rafael Lima. A simplificação no direito administrativo e ambiental (de acordo com a lei no 13.874/2019 - "Lei da Liberdade Econômica"). Rio de Janeiro, Lumen Juris, 2020.

DICKERSON, Steven L.. «The Evolving Federal Wetland Program», Sw. L.J., vol. 44, 1990-1991.

ENETJÄRN, Anders et al., Environmental compensation: Key conditions for increased and cost effective application, Nordic Council of Ministers, Copenhagen, 2015. Kindle Edition, (2.1).

FIGUEIREDO, Guilherme José Purvin de. Curso de direito ambiental. 5a ed. São Paulo: Editora Revista dos Tribunais. 2012.

GARCIA, Flávio Amaral. Licitações e contratos administrativos: casos e polêmicas. 4a ed.. São Paulo, Malheiros, 2016.

GUERRA, Sérgio; DE PALMA, Juliana Bonacorsi, Art. 26 da LINDB: Novo regime jurídico de negociação com a Administração Pública. Revista de Direito Administrativo, Rio de Janeiro, Edição Especial: Direito Público na Lei de Introdução às Normas de Direito Brasileiro - LINDB (Lei n 13.655/2018), nov. 2018.

HILDRETH, Richard G.. «Managing Ocean Resources: Canada», Int'l J. Estuarine \& Coastal L., vol. 6, 1991.

JUSTEN FILHO, Marçal. Curso de Direito Administrativo. 9ạ ed. atual e ampl.. São Paulo, Revista dos Tribunais, 2013.

KRUGER, Toby. "The Canadian Environmental Assessment Act and Global Climate Change: Rethinking Significance», Alta. L. Rev., vol. 47, 2009-2010. 
MACHADO, Paulo Affonso Leme, Direito Ambiental Brasileiro. 12a ed.. São Paulo, Malheiros, 2004.

MEIRELLES, Hely Lopes. Direito Administrativo Brasileiro. 36a ed.. São Paulo: Malheiros, 2010.

MILARÉ, Édis. Direito do Ambiente. 8ª ed. São Paulo, Editora Revista dos Tribunais, 2013.

MILARÉ, Édis. Direito do Ambiente, 10ª ed.. São Paulo, Editora Revista dos Tribunais, 2015.

OECD, Biodiversity Offsets: effective design and implementation, OECD Publishing, Paris, 2016

O'SHEA, Shannon, «Lucas Leaves Room for Categorical Defenses for Regulations of Wetlands that Are Critical to Water Resources and Essential for Public Drinking», in FIU L. Rev., vol. 5, 2009-2010.

OWLEY, Jessica. «Preservation is a Flawed Mitigation Strategy», Ecology L. Currents, vol. 42, 2015.

TURNER, Stephanie. "Coastal Management and the Environmental Compensation Challenge», N.Z.J. Envtl. L., vol. 4, 2000.

VELTMAN, Virginia C.. "Banking on the Future of Wetlands Using Federal Law», Nw. U. L. Rev., vol. 89, 1994-1995.

WILLIAMS, Austin. «The Pacific Salmon Treaty: A Historical Analysis and Prescription for the Future», J. Envtl. L. \& Litig., vol. 22, 2007. 